\title{
Management of Bladder Exstrophy: A Case Report in the Urological Ward at Saint Elizabeth General Catholic Hospital SHISONG
}

\author{
Cisse Demba1,2*, Barry Mamadou II', Kante Daouda1, Bah Ibrahima1, Bah Mamadou Diawo1, \\ Diallo Thierno Mamadou Oury¹, Bah Mamadou Bissiriou' ${ }^{1}$, Fofana Houssein'2, Fomonyuy Edwin'2, \\ Cherif Mahamoud Sama², Diallo Ab' ${ }^{1}$, Bah Oumar Raphiou' \\ ${ }^{1}$ Faculty of Health Sciences and Techniques, Gamal Abdel Nasser University of Conakry, Conakry, Guinea \\ ${ }^{2}$ Shisong Hospital, Kumbo, Cameroon \\ Email: *adembacisse74@gmail.com
}

How to cite this paper: Demba, C., Mamadou II, B., Daouda, K., Ibrahima, B., Diawo, B.M., Oury, D.T.M., Bissiriou, B.M., Houssein, F., Edwin, F., Sama, C.M., Ab, D. and Raphiou, B.O. (2019) Management of Bladder Exstrophy: A Case Report in the Urological Ward at Saint Elizabeth General Catholic Hospital SHISONG. Open Journal of Urology, 9, 162-166. https://doi.org/10.4236/oju.2019.910019

Received: July 2, 2019

Accepted: October 14, 2019

Published: October 17, 2019

\section{Copyright $\odot 2019$ by author(s) and} Scientific Research Publishing Inc. This work is licensed under the Creative Commons Attribution International License (CC BY 4.0).

http://creativecommons.org/licenses/by/4.0/

\begin{abstract}
Bladder Extrophy is a rare urogenital malformation of the penis and bladder. This is an impressive fact at birth, due to the absence of the anterior bladder wall and the dorsal side of the penis. We report the clinical observation of a 21-month-old child who consults for urine incontinence from birth, when physical examination showed complete bladder extrophy. The reconstructive surgery allowed forming a bladder reservoir associated with a repair of the penis at the same time. Bladder extrophy is a benign condition whose operative consequences can be simple but urinary incontinence is not uncommon after reconstitution.
\end{abstract}

\section{Keywords}

Extrophy, Penis, Bladder, Malformation

\section{Introduction}

Bladder exstrophy is a urogenital malformation characterized by an abnormality of the cloacal membrane that forms the intra-umbilical abdominal wall during the first weeks of embryonic life.

It presents itself under 3 aspects: the classical form or complete vesical extrophy, the partial form which is rare and the extended form known as extrophy of the cloaca also very rare [1] [2] [3].

In Africa, the presence of an apparent malformation is often interpreted as a 
curse or the result of witchcraft.

In addition, there are also socio-economic factors and the lack of qualified medical personnel in peripheral health facilities with the result that pregnant women cannot properly follow their pregnancies in a health facility in order to detect possible malformation in time during the antenatal period

Bladder exstrophy, diagnosed during the morphological examination in the 2nd trimester of pregnancy may be a reason for voluntary termination of pregnancy [4] [5].

Bladder exstrophy is a rare pathology; its frequency is estimated at 1 in 10,000 to 50,000 births [6].

It affects about one in 40,000 infants according to the Boston Children's Hospital in the United States of America [5].

We report the clinical case of a newborn having a complete bladder exstrophy received and treated in our hospital and make a review of the literature.

\section{Observation}

It was a 21-month-old male child who had been referred to us from a rural health center on the outskirts of Bamenda in North West Region of Cameroon.

At birth, the malformation was obvious and after several unsuccessful consultations in health facilities in the region, he was sent to us for management

The study of his antecedents had revealed that he was the last born in family of three and no malformation had been revealed in his brothers. Similarly, there was no concept of consanguinity between the parents. No ultrasound examination documented the pregnancy follow-up of the mother, who said that she had done her prenatal consultations correctly.

The clinical examination revealed a conscious child in good general condition with normal reflexes.

At the hypogastric level, the presence of a reddish plate was noted with the presence of the two ureteral orifices measuring $11 \mathrm{~cm}$ long axis each through which intermittently flowed urine associated with the absence of the dorsal face of the penis (Figure 1). There was also a diastasis of the right muscles in the lower abdominal wall, a displaced navel. The examination expanded to other organs did not reveal other apparent malformations.

The renal blood test was normal with serum creatinine at $5 \mathrm{mg} / \mathrm{L}$ and there was no urinary infection on the cyto-bacteriological examination of the urine. The abdominal and pelvic ultrasound did not visualize the bladder because of acoustic window and there was no renal dilation.

In order to obtain a reservoir, a primary surgical closure of the exstrophy and epispadia associated with reconstruction of the anterior abdominal wall without osteotomy was performed. The patient was seen at 3 months with a micturition jet but we could not judge the urinary continence because at this age the child does not yet have micturition autonomy (Figure 2). It was planned a control at 6 months, 1 year, and 5 years but the appointment was not respected. 


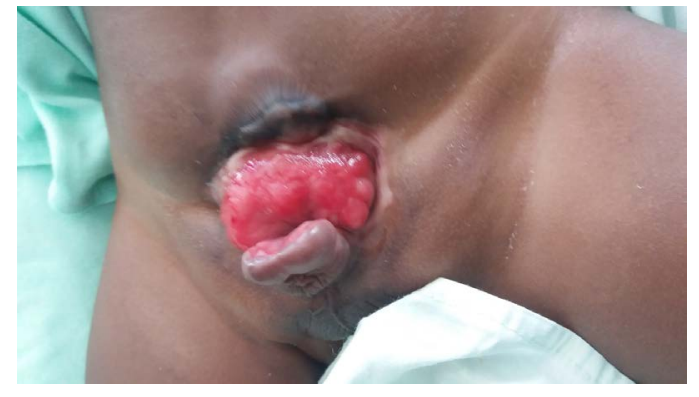

Figure 1. Before intervention.

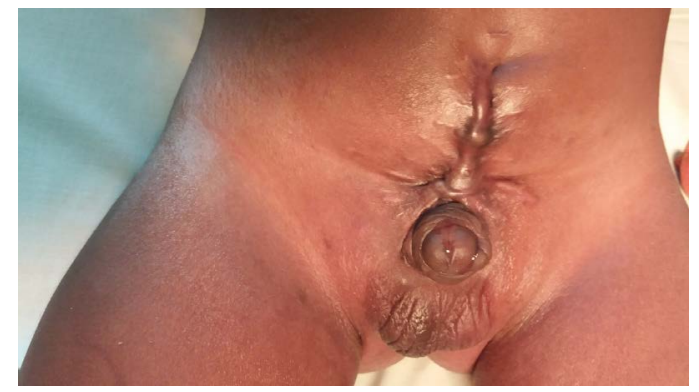

Figure 2. After intervention.

\section{Discussion}

Exstrophy of the bladder is a birth defect. It is a rare malformation that affects about one in 40,000 infants according to the Boston Children's Hospital [6].

Exstrophy of the bladder is an apparent malformation discovered at birth. In our case the patient was consulted after 21 months of birth with a bladder dry and retracted.

In developed countries, this pathology is diagnosed during the antenatal life and this intervention is carried out, ideally at $24-48$ after birth.

The clinical examination of our patient revealed: a diastasis of the straight muscles in the lower abdominal wall, a displaced navel, an inflammatory bladder plate and an associated penile epispadia.

In the literature, in addition to the clinical data of our patient, there is often a diastasis of the associated pubis and in the girl a short urethra, extended labia and a narrow vaginal opening [6] [7]. We did not observe any diastasis of pubic bones in our patient who had good walking.

The work up (urea and blood creatinine, cytobacteriological examination of the urine, radiography of the pelvis and ultrasound of the urinary system) were to check urinary infection, signs of renal insufficiency and the presence of other associated malformations.

Therapeutically, two positions are opposed in the literature:

The first consists of primary closure of the bladder and urethral plate, reconstruction of the lower abdominal wall, and approximation of the pubic bones with or without osteotomy. This has the advantage that it realizes a bladder tank early enough, thus ensuring good healing of the bladder plate and good recovery of continence later. However, it has the disadvantage of being a heavy surgery at 
this age requiring a long anesthesia, and traumatizes the children.

The other approach is to correct the malformation by successive interventions carried out at different ages of the child:

- Closure of the bladder and urethral plate and reconstruction of the lower abdominal wall at first leaving the child with epispadia and incontinence at maximum 48 hours of birth,

- Correction of the epispadia at 6 months after hormonal stimulation in a second time and

- Surgery for the incontinence and vesical-kidney reflux at 4 - 5 years of age [8] [9].

In our case, the patient's non-compliance with appointments did not reveal the possibility of performing an enlargement cystoplasty or an uretero-vesical reimplantation.

In any case, taking into account the parents' expectations and the psychosocial discomfort that this malformation may cause in the child, this surgery must be performed at best by a qualified surgeon with a certain experience in the field and with equipment adapted to this type of surgery, which is not always the case in some African countries [5].

In our case, despite the fact that it was a 21 -month-old child, the operative follow-ups were a success, particularly the repair of the bladder and the urethra as first-line treatment.

The long-term follow-up of our patient would have allowed us to judge the opportunity to perform an ureterovesical reimplantation. The latter, however, is almost always indicated because the majority of these children still have vesico-renal reflux, which can lead to a deterioration of renal function [8].

\section{Conclusions}

Bladder exstrophy is an apparent malformation that can be diagnosed on prenatal ultrasound in the first trimester and can lead to pregnancy termination in countries with low skills.

When diagnosed at birth, well-managed surgical management can give a good morpho-functional result.

\section{Conflicts of Interest}

The authors declare no conflicts of interest regarding the publication of this paper.

\section{References}

[1] Bankole Sanni, R., Coulibaly Denoulet, D. and Modibo, M.L. (1997) Treatment of Vesical Extrophy at Abidjan University Hospital (Treichville). Annales d'Urologie, 31, 371-374.

[2] Belkacem, R., Kriouile, Y. and Outarahout, O. (1998) Current Treatment of Bladder Extrophy: About 31 Cases. Médecine du Maghreb, No 72.

[3] Furtos, C., Chene, G., Varlet, M.N., Varlet, F., Seffert, P. and Chauleur, C. (2010) 
Antenatal Diagnosis and Management of Isolated Bladder Extrophytes. Gynecology Obstetrics and Infertility, 38, :624-630. https://doi.org/10.1016/j.gyobfe.2010.08.027

[4] Melin, Y. and Cendron, J. (1990) Vesical Malformations and Bladder Exstrophies. EMC-Urologie: 1-0 [Article 18-208-A-10].

[5] Nerli, R.B., Kamat, G.V., Alur, S.S., Koura, A., Prabha, V. and Amarkhed, S.S. (2008) Bladder Extrophy in Adulthood. Indian Journal of Urology, 24, 164-164. https://doi.org/10.4103/0970-1591.40609

[6] Traore, M.T., Niang, L., Jalloh, M., Ndow, M., Labou, I. and Gueye, S.M. (2016) Management of Vesical Extrophy about 7 Cases. Uro Andro, 1.

[7] Tshimbayi, M., Ndua, D., Kazodi, C., Shamashanga, K.L., Bugeme, M., Kiopine, M.P. and Mukulu, O. (2014) Bladder Extrophy: About a Late Diagnosis. Pan African Medical Journal, 17, 172.

[8] Siffel, C., Correa, A., Amar, E., Bakker, M.K., Bermejo-Sanchez, E., Bianca, S., et al. (2011) Bladder Extrophy: An Epidemiologic Study from the International Clearinghouse for Birth Defects Surveillance and Research, and an Overview of the Literature. American Journal of Medical Genetics Part C: Seminars in Medical Genetics, 157, 321-332. https://doi.org/10.1002/ajmg.c.30316

[9] Ziouziou, A. and Andalousi. I.A. (2014) Adult Bladder Extrophy: About 5 Cases. African Journal of Urology, 20, 53-58. 